\title{
Respostas fisiológicas de clones de eucalipto cultivados em casa de vegetação sob deficiência hídrica
}

\author{
Physiological responses of eucalyptus clones grown in a greenhouse under water deficit
}

\section{Emanuel Tássio Fernandes ${ }^{\mathrm{I}}$ Paulo Araquém Ramos Cairo ${ }^{\mathrm{II}}$ Adalberto Brito de Novaes ${ }^{\mathrm{II}}$}

\section{RESUMO}

\begin{abstract}
Os prolongados períodos de seca no Sudoeste da Bahia podem causar prejuízos ao cultivo de eucalipto, que é a principal espécie florestal cultivada nessa região. Com o propósito de se conhecer o desempenho de alguns clones de eucalipto, face às restrições hídricas dessa região, realizou-se um experimento em casa de vegetação, no qual foram avaliadas respostas fisiológicas de quatro clones de eucalipto à baixa disponibilidade de água no solo. Utilizou-se delineamento inteiramente ao acaso, no qual os tratamentos constituíram um arranjo fatorial $4 \times 2$ (clones VM01, VCC0865, AEC0144 e AEC0224, sob regimes hídricos irrigado e não irrigado), com quatro repetições e duas plantas por parcela. Mudas com 90 dias de idade foram aclimatadas em casa de vegetação e irrigadas durante 60 dias. Após esse período, suspendeu-se a irrigação para um grupo de plantas, dando início às avaliações de potencial hídrico foliar $(\Psi w)$, teor relativo de água (TRA), transpiração (E), condutância estomática ( $\mathrm{gs})$ fotossíntese (A) e concentração interna de $\mathrm{CO}_{2}$ (Ci). A deficiência hídrica causou alterações significativas em todas as variáveis avaliadas: $\Psi w, T R A, \mathrm{E}, \mathrm{gs}$ e A sofreram decréscimos, ao passo que Ci aumentou. As reduções em $\Psi$ w e TRA não registraram diferenças significativas entre os clones. Em relação a A, essa redução foi menor no clone VMO1.
\end{abstract}

Palavras-chave: Eucalyptus spp., relações hídricas, fotossíntese.

\section{ABSTRACT}

The long dry periods in Bahia Southwest can harm the eucalyptus cultivation, which is the most important forestry specie cultivated in this region. This research aimed to evaluate the physiological responses of eucalyptus clones, grown in a greenhouse under water deficit. The experiment was carried out in a completely randomized design, and the treatments were a factorial 4x2 (VMO1, VCC0865, AEC0144 and AEC0224 clones, under irrigated and non irrigated water regimes) with four replications and two plants per plot. The seedlings were 90 days old and the acclimation was carried out in a greenhouse, with irrigation, for 60 days. After the acclimation, irrigation was interrupted to a group of plants, and the following evaluations were started: leaf water potential $(\Psi w)$, water relative content (TRA), transpiration (E), stomatal conductance (gs), photosynthesis (A) and $\mathrm{CO}_{2}$ internal concentration (Ci). Significant changes were observed in all variables. There was a decrease in $\Psi w, T R A, E$, gs and $A$, whereas increased $C i$. The $\Psi_{w}$ and TRA decreases showed no significant differences among the clones. In relation to $A$, this decrease was lower in VMO1 clone.

Key words: Eucalyptus spp., water relations, photosynthesis.

\section{INTRODUÇÃO}

O eucalipto encontrou no solo e no clima brasileiro as condições ideais para produção em larga escala e, devido à sua grande capacidade de adaptação e diversidade de uso, tornou-se a principal espécie utilizada para a formação de florestas plantadas no país, ocupando uma área superior a 4,0 milhões de hectares (ABRAF, 2011).

Antes concentrada nas regiões mais úmidas, as atividades florestais atualmente se estendem ao semiárido nordestino, particularmente no Sudoeste da Bahia, que é uma região sujeita a períodos prolongados de seca. Segundo SOUZA et al. (2001), entre todos os recursos de que as plantas precisam, a água é o mais limitante para a produtividade agrícola, por ser essencial aos diversos processos metabólicos das plantas, principalmente durante o período inicial de desenvolvimento.

\footnotetext{
'Universidade Estadual do Sudoeste da Bahia (UESB), 45031-900, Vitória da Conquista, BA, Brasil. E-mail: emanueltassio@ yahoo.com.br. Autor para correspondência.

IIDepartamento de Fitotecnia e Zootecnia, UESB, Vitória da Conquista, BA, Brasil. 
Os efeitos da deficiência hídrica sobre as plantas são complexos, não havendo um mecanismo padrão de resistência à seca. As plantas respondem a essa condição por meio de vários processos adaptativos, como a capacidade de reduzir o potencial hídrico, aliada a adaptações morfológicas, anatômicas e fisiológicas (NOGUEIRA et al., 2005). A primeira e mais sensível resposta à deficiência hídrica é a diminuição da turgescência celular, que provoca o fechamento dos estômatos e a redução da fotossíntese (LARCHER, 2006).

Alguns clones de eucalipto sob diferentes regimes hídricos apresentam redução dos valores de fotossíntese, condutância estomática e transpiração (TATAGIBA et al., 2008). O fechamento parcial dos estômatos é uma conhecida estratégia de tolerância das plantas à deficiência hídrica, porque diminui a taxa de transpiração, mantém o conteúdo hídrico foliar, reduz o risco de desidratação e eventual morte por dessecação (PEAK et al., 2004). Contudo, além do controle estomático, a baixa condutância difusiva do mesofilo pode se constituir, também, em limitação à assimilação de $\mathrm{CO}_{2}$ (PEEVA \& CORNIC, 2009).

O presente trabalho teve como objetivo avaliar o desempenho de quatro clones de eucalipto submetidos a diferentes regimes hídricos.

\section{MATERIAL E MÉTODOS}

O experimento foi realizado em casa de vegetação, na Universidade Estadual do Sudoeste da Bahia, em Vitória da Conquista - BA, no período de 29 de novembro de 2010 a 18 de fevereiro de 2011. Foram utilizadas mudas de eucalipto com 90 dias de idade, produzidas pelas empresas florestais Tecnoplant e Plantflora, provenientes de quatro clones dos seguintes genótipos: VM01 (híbrido de $\boldsymbol{E}$. urophylla x E. camaldulensis), VCC0865 (híbrido de $\boldsymbol{E}$. urophylla $\mathrm{x}$ E. grandis), AEC0144 e AEC0224 (ambos de $\boldsymbol{E}$. urophylla).

As mudas passaram por uma seleção quanto à uniformidade e foram transplantadas para vasos contendo $23 \mathrm{~kg}$ de solo Latossolo VermelhoAmarelo, cuja análise química apontou $\mathrm{pH}=5,7$, $\mathrm{P} \quad($ Mehlich $)=1 \mathrm{mg} \mathrm{dm}^{-3}, \quad \mathrm{M} . \mathrm{O}=22, \quad \mathrm{~V}(\%)=61$ e as seguintes concentrações $\left(\mathrm{Cmol}_{c} \cdot \mathrm{dm}^{-3}\right.$ solo): $\mathrm{H}+\mathrm{Al}=2,2 ; \mathrm{K}^{+}=0,10 ; \mathrm{Ca}^{2+}=2,4 ; \mathrm{Mg}^{2+}=0,9 ; \mathrm{SB}=3,4 \mathrm{e}$ $\mathrm{CTC}=5,6$. $\mathrm{O}$ solo foi retirado à profundidade de 30 a $40 \mathrm{~cm}$, seco ao ar, destorroado e posteriormente mantido com teor de umidade próximo à capacidade de campo, definida como a máxima retenção de água no substrato, após a drenagem do seu excesso (BERNARDO et al., 2005). O monitoramento do teor de umidade do solo foi realizado com base na verificação diária do peso dos vasos.

Com base na análise de solo e de acordo com as recomendações de SILVEIRA et al. (2001), foi feita a adubação no transplantio, de modo a fornecer 3,13mg de fósforo por quilo de solo, aplicados na forma de superfosfato simples e, aos 45 dias após o transplantio, foi realizada adubação de cobertura, fornecendo $0,10 \mathrm{mg}$ de nitrogênio e $0,13 \mathrm{mg}$ de potássio por quilo de solo, nas formas de ureia e cloreto de potássio, respectivamente.

As mudas foram submetidas a um período de adaptação de 60 dias nos vasos, em casa de vegetação, recebendo irrigação diária, suficiente para manter o solo em condições próximas à capacidade de campo, quando, então, foram iniciados os manejos de irrigação diferenciados até o final do experimento, que durou cerca de 80 dias.

Os regimes hídricos aplicados foram o irrigado, em que a umidade do substrato foi mantida próxima à capacidade de campo, e o não irrigado, em que a irrigação foi suspensa após o período de adaptação, mantendo-se essa condição até o final do experimento (20 dias sem irrigação). Durante o experimento, a temperatura média na casa de vegetação foi de $26^{\circ} \mathrm{C}$ e radiação média de $291,6 \mu \mathrm{mol}$ $\mathrm{m}^{-2} \mathrm{~s}^{-1}$.

O delineamento experimental foi inteiramente casualizado (DIC), com quatro repetições, sendo os tratamentos arranjados segundo o esquema fatorial $4 \times 2$, com quatro clones de eucalipto e dois regimes hídricos, considerando-se duas plantas por unidade experimental, totalizando 64 plantas.

Após a diferenciação dos regimes hídricos, foram avaliados o potencial hídrico foliar $\left(\Psi_{\mathrm{w}}\right)$, teor relativo de água, condutância estomática $(g s)$, transpiração $(E)$, concentração interna de $\mathrm{CO}_{2}(\mathrm{Ci})$ e fotossíntese líquida $(A)$. Para a determinação do $\Psi$ w, utilizou-se uma bomba de pressão (SCHOLANDER et al., 1965), em duas folhas completamente expandidas, sendo uma de cada planta da unidade experimental, localizadas na parte mediana da parte aérea, coletadas às 4h30min da manhã. Com as mesmas folhas utilizadas nas avaliações de $\Psi_{\mathrm{w}}$, foram retirados 10 discos foliares e registrou-se o peso da sua massa fresca (PF) em uma balança de precisão. Os discos foliares foram submersos em água deionizada por 24h, a fim de se obter o peso do material túrgido (PT). Posteriormente, os discos foliares foram submetidos à secagem em estufa de circulação forçada de ar, sob temperatura de $70^{\circ} \mathrm{C}$, durante 48 horas, para se obter o peso do material seco (PS). O teor relativo de água foi determinado com base na seguinte fórmula: 
TRA $=[($ PF-PS $) /($ PT-PS $)] \times 100$, cujos resultados foram expressos em valores percentuais (\%). As verificações de $\Psi_{\mathrm{w}}$ e TRA foram realizadas a cada três dias, a fim de monitorar as relações hídricas até o final do experimento, aos 20 dias após a suspensão da irrigação, quando as plantas sob restrição hídrica atingiram o nível de estresse considerado crítico, o qual se caracterizou pelo intenso murchamento de folhas. Os dados correspondentes às leituras realizadas no final do experimento foram utilizados para avaliações comparativas entre os clones e os regimes hídricos.

Os valores de $g s, E, \mathrm{Ci}$ e $A$ foram obtidos por avaliações de trocas gasosas com um medidor portátil de fotossíntese, do tipo analisador infravermelho de gases (modelo IRGALI-6400, LI-COR ${ }^{\circledR}$, Nebrasca/USA). Dentro da casa de vegetação, as plantas receberam, durante a mensuração, irradiância de aproximadamente $900 \mathrm{mmol}$ de fótons $\mathrm{m}^{-2} \mathrm{~s}^{-1}$. Esse valor foi determinado pela curva de saturação luminosa medida para o eucalipto, situando-se entre 800 e $1.000 \mathrm{mmol}$ de fótons $\mathrm{m}^{-2} \mathrm{~s}^{-1}$, conforme SILVA et al. (1998). Foram realizadas leituras a cada três dias, entre $9 \mathrm{~h}$ e $10 \mathrm{~h} 30 \mathrm{~min}$ da manhã, em folhas do terço médio de cada planta da unidade experimental, com o propósito de monitorar o comportamento fisiológico das plantas. Os dados correspondentes às leituras realizadas no final do experimento foram utilizados para avaliações comparativas entre os clones e os regimes hídricos.
Para a análise estatística, os dados foram submetidos à análise de variância (ANOVA). As médias e os desdobramentos das interações, ocorridos entre os tratamentos, foram comparados pelo teste Tukey, a 5\% de probabilidade, utilizando o programa estatístico SAEG, versão 9.1. Para as variáveis que apresentaram efeito significativo do manejo hídrico, foi feito o teste de comparação de médias pelo teste $\mathrm{F}$ e, para clones, pelo teste Tukey.

As médias que não se enquadraram no princípio da normalidade sofreram transformações, para fins de análises estatísticas. Dentre as variáveis, foram transformados os dados de fotossíntese líquida (A), pela expressão raiz [raiz $(x)]$; e potencial hídrico $\left(\Psi_{\mathrm{w}}\right)$ e concentração interna de $\mathrm{CO}_{2}(\mathrm{Ci})$, pela expressão $[\log (x .100)]$. Nas figuras que ilustram essas variáveis, foram utilizados os dados transformados.

\section{RESULTADOS E DISCUSSÃO}

As análises estatísticas evidenciaram diferenças significativas entre os regimes hídricos para todas as características avaliadas. Apenas para o TRA não houve interação clone $\mathrm{x}$ regime hídrico.

Os valores de $\Psi_{\mathrm{w}}$ variaram entre os clones irrigados (Figura 1). Contudo, as diferenças observadas entre os clones nesse regime hídrico, apesar de significativas, podem ser consideradas como de pequena amplitude, registrando maiores

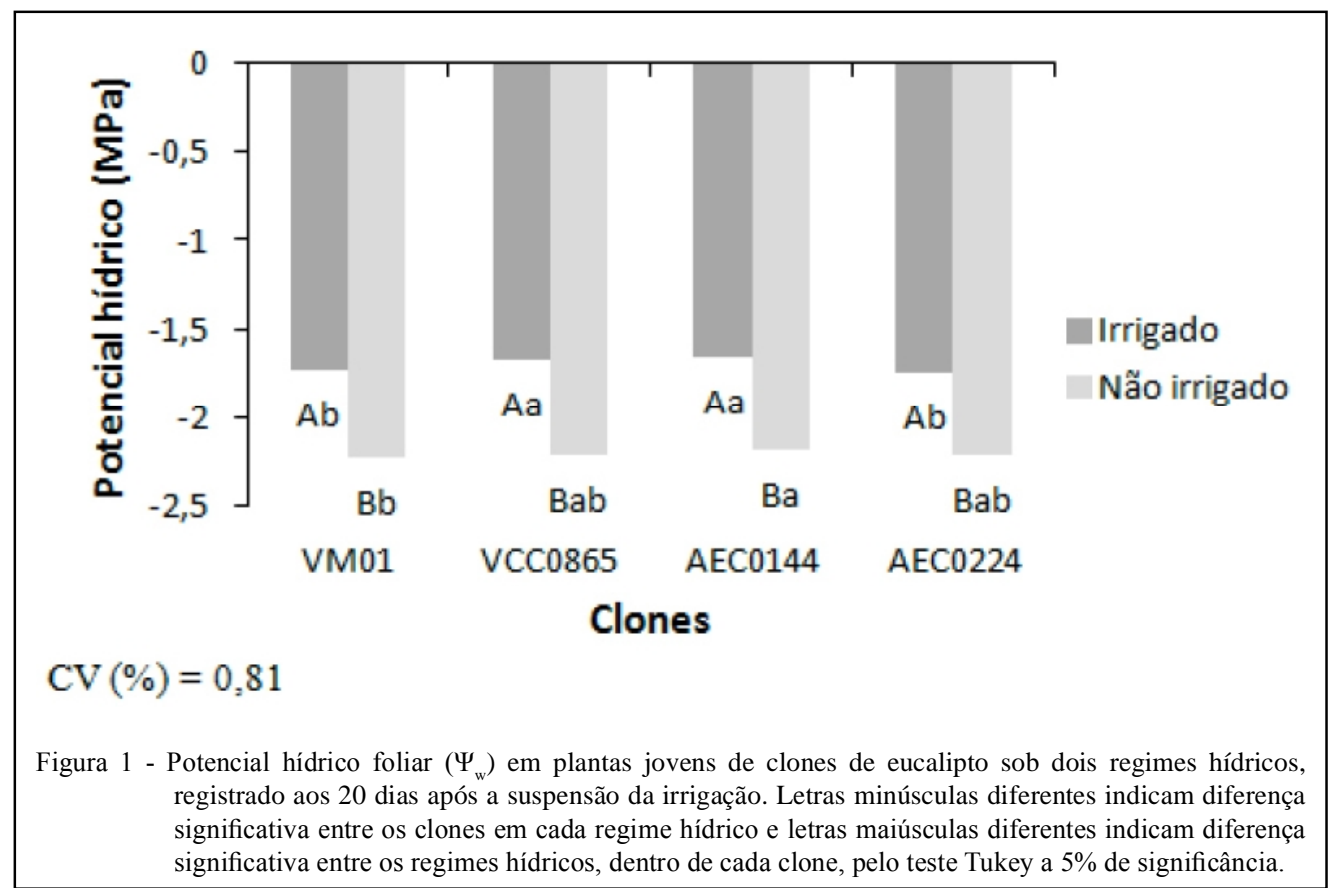

Ciência Rural, v.45, n.1, jan, 2015. 
valores de $\Psi_{w}$ para os clones VCC0865 e AEC0144, em comparação aos clones VM01 e AEC0224. Em relação ao tratamento não irrigado, houve diferença apenas entre VM01 e AEC0144, sendo que, neste último clone, os valores de $\Psi_{\mathrm{w}}$ foram mais elevados. Reduções de $\Psi_{w}$ também foram observadas por CHAVES et al. (2004) em plantas de eucalipto com quatro meses de idade, submetidas à suspensão da irrigação, até ocorrer intenso murchamento de folhas.

Todos os clones apresentaram declínio do $\Psi_{\mathrm{w}}$ no tratamento não irrigado, e isso pode ter sido resultante de alterações bioquímicas que levam a mudanças na concentração do suco celular, mas também pode resultar da diminuição do volume das células das folhas, como consequência de restrições hídricas crescentes no solo, que inviabilizam o fornecimento de água às plantas (PALLARDY, 2008).

Para o TRA, houve efeito significativo para clones e regimes hídricos (Figura 2). Os clones VM01 e AEC0144 apresentaram TRA significativamente mais elevados que os do clone VCC0865, indicando maior capacidade de armazenamento de água em suas células. Em todos os clones, a suspensão da irrigação provocou reduções no TRA, cujo valor médio foi de $67,78 \%$. O fato de a suspensão da irrigação ter causado reduções significativas, tanto em $\Psi_{\mathrm{w}}$ como em TRA, sugere que o ajustamento osmótico não é o mecanismo que estes clones de eucalipto usam para manter o status hídrico quando cultivados sob deficiência hídrica. Em condições naturais, a deficiência hídrica geralmente evolui de maneira gradual, enquanto, em ensaios de plantas em vasos, a imposição do déficit geralmente é muito rápida, em razão da área de restrição radicial. Por este motivo, alguns mecanismos adaptativos, como o acúmulo de substâncias osmoticamente ativas nas células e posterior redução do potencial osmótico, ou não ocorrem ou se manifestam com menor intensidade
(CARVALHO, 2005), o que permitiria discriminar melhor eventuais variações genotípicas.

No que se refere a gs e $E$ (Figura 3), sob o regime irrigado, os clones AEC0144 e AEC0224 apresentaram valores superiores aos dos clones VM01 e VCC0865, sugerindo maior consumo de água. Sob deficiência hídrica, todos os clones reduziram bastante a transpiração e a condutância estomática, sem diferenças significativas entre os clones. A redução da condutância estomática também foi observada por SILVA et al. (2008) em plantas de jovens de aroeira, cultivadas em vasos, sob deficiência hídrica. No presente trabalho, os resultados confirmam estudos realizados por TATAGIBA et al. (2007), que já haviam observado eficiente controle estomático de plantas de eucalipto, com idade entre 2,5 e 3 anos, sob restrições hídricas. Segundo LIMA (1996), o eucalipto pode tolerar uma amplitude de variação do potencial hídrico foliar sem alterar significativamente a condutância estomática. Porém, quando o valor crítico de potencial hídrico foliar é atingido, os estômatos começam a se fechar substancialmente, até quase o fechamento total. No presente trabalho, os resultados sugerem que esse valor crítico tenha sido atingido (Figura 1), tendo em vista as reduções bastante significativas dos valores de gs e $E$ em todos os clones sob restrições hídricas.

Mesmo sob irrigação plena, os clones apresentaram diferenças em suas taxas de fotossíntese líquida (Figura 3). Os clones AEC0144 e AEC0224 apresentaram taxas superiores às dos clones VM01 e VCC0865. A suspensão da irrigação causou declínio significativo na fotossíntese líquida em todos os clones, atingindo taxas entre 1,0 e $1,5 \mu \mathrm{molCO}_{2} \mathrm{~m}^{-2}$ $\mathrm{s}^{-1}$. Contudo, sob restrições hídricas, esse declínio foi proporcionalmente menor no clone VM01, o qual registrou taxas de fotossíntese líquida superiores às dos demais clones.
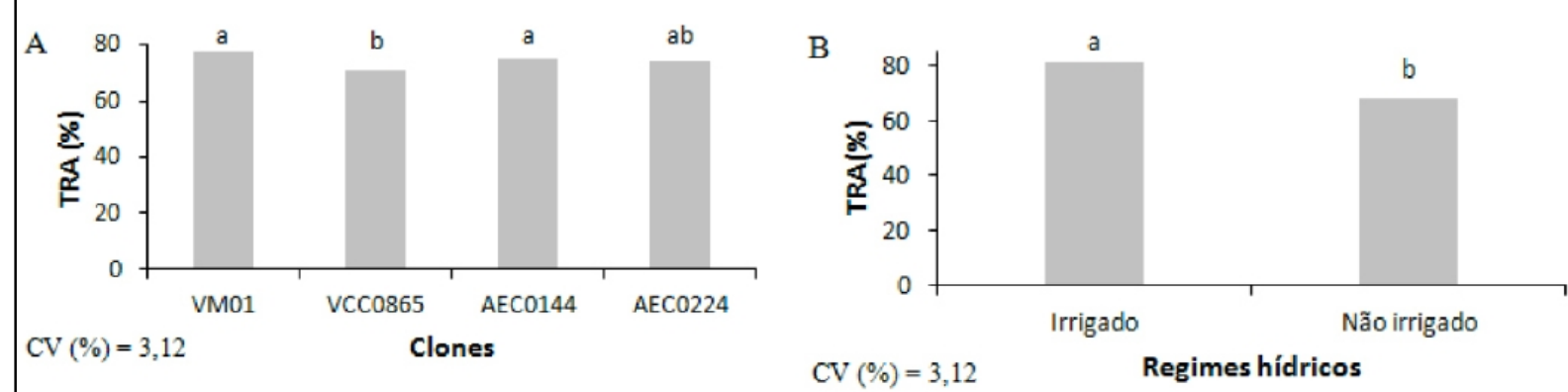

Figura 2 - Teor relativo de água (TRA) em plantas jovens de quatro clones de eucalipto sob dois regimes hídricos, registrado aos 20 dias após a suspensão da irrigação. (A) representa comparação entre clones, e (B) entre regimes hídricos. Médias seguidas de mesma letra não diferem entre si pelo teste Tukey a 5\% de significância entre os clones e pelo teste $\mathrm{F}$ a $5 \%$ entre os regimes hídricos. 


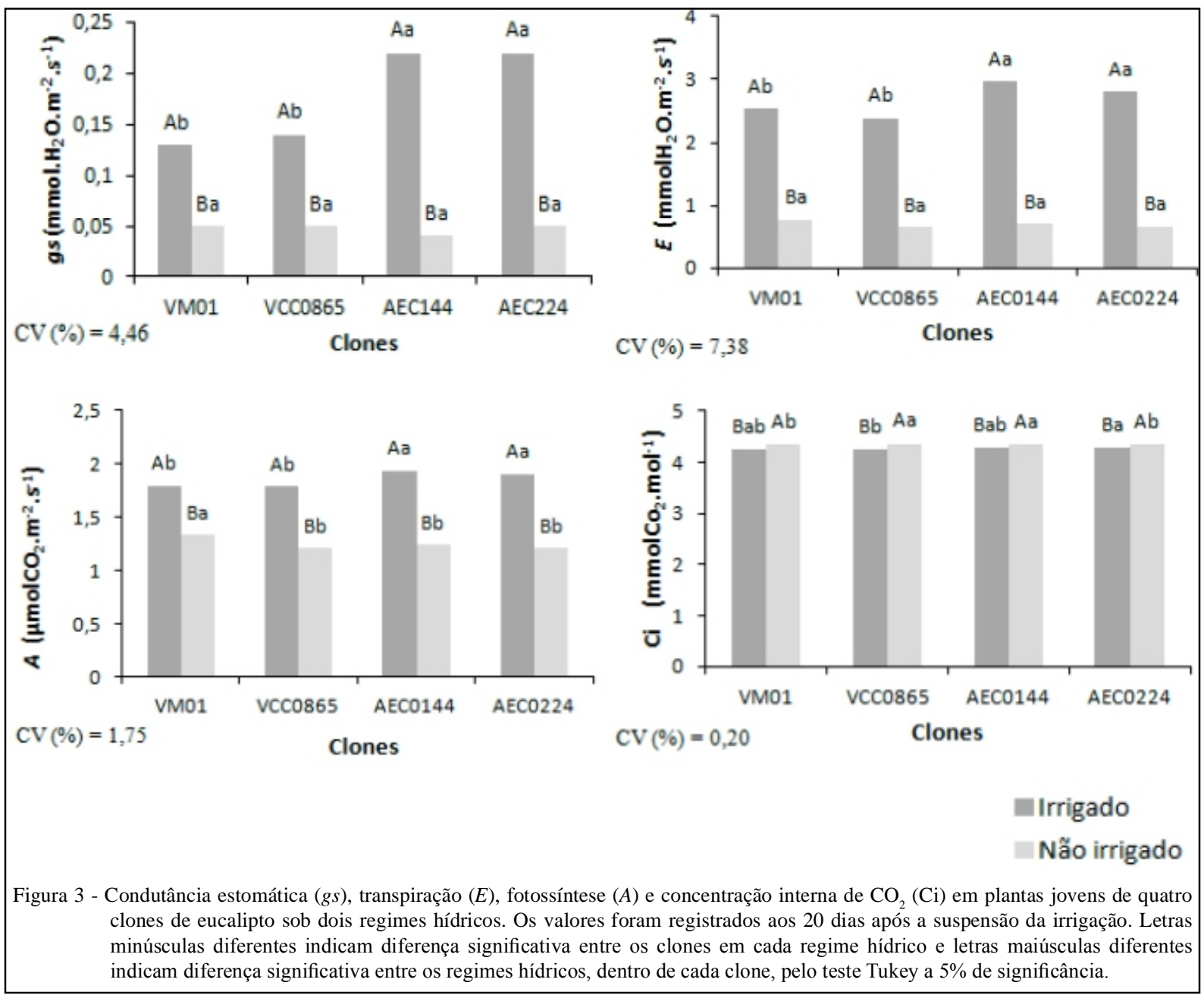

Considerando-se exclusivamente as plantas do tratamento irrigado, houve diferença significativa de Ci (Figura 3) apenas entre os clones VCC0865 (maior) e AEC0224 (menor). Em todos os clones, a $\mathrm{Ci}$ em plantas sob deficiência hídrica foi maior que em plantas irrigadas. A despeito da queda nas taxas de fotossíntese líquida, a elevação da $\mathrm{Ci}$ pode ser justificada por baixa condutância do mesofilo, a qual reduz a capacidade difusiva de $\mathrm{CO}_{2}$ (PEEVA \& CORNIC, 2009). O acúmulo desse gás na câmara subestomática provoca o fechamento dos estômatos, resultando na inibição da condutância estomática. O mecanismo exato pelo qual a alta concentração de $\mathrm{CO}_{2}$ na câmara subestomática provoca o fechamento dos estômatos ainda não está bem caracterizado (LARCHER, 2006). O aumento da $\mathrm{Ci}$, sob baixos valores de potencial hídrico foliar e baixa condutância estomática, pode estar relacionado a um decréscimo na eficiência de carboxilação e limitação da regeneração de ribulose-1,5bi-fosfato
(NI \& PALLARDY, 1992; LAWLOR, 2002). Por outro lado, CHAVES et al. (2002) e LAWLOR \& CORNIC (2002) não renegam o impacto dos efeitos metabólicos sobre a atividade fotossintética em plantas sob deficiência hídrica, mas consideram que esta seja uma segunda linha de resposta, pois acreditam que a limitação da fotossíntese é principalmente devido à menor difusão de $\mathrm{CO}_{2}$, que pode ser causada tanto pela resistência mesofílica, como pelo fechamento estomático.

\section{CONCLUSÃO}

Sob condições normais de irrigação, os clones AEC0144 e AEC0224 apresentaram maiores taxas de fotossíntese, condutância estomática e transpiração. O status hídrico das plantas, representado conjuntamente pelo potencial hídrico foliar e pelo teor relativo de água, foi bastante afetado pela restrição hídrica, que também promoveu 
reduções significativas na condutância estomática e na transpiração. De forma geral, sob restrições hídricas, os clones apresentaram desempenhos similares entre si, porém, o clone VM01 apresentou redução da fotossíntese líquida em menor proporção.

\section{REFERÊNCIAS}

ABRAF. Anuário Estatístico da ABRAF: ano base 2010/ABRAF. Brasília: DF, 2011. 130 p.

BERNARDO, S. et al. Manual de irrigação. 7.ed. Viçosa: UFV, 2005. 611p.

CARVALHO, C.J.R. Respostas de plantas de Schizolobium amazonicum (S. parahyba var: amazonicum) e Schizolobium parahyba (Schizolobium parahybum) à deficiência hídrica. Revista Árvore, v.29, n.6, p.907-914, 2005. Disponível em: <http://dx.doi.org/10.1590/S0100-67622005000600009>. Acesso em: 14 nov. 2011. doi: 10.1590/S0100-67622005000600009.

CHAVES, J.H. et al. Seleção precoce de clones de eucalipto para ambientes com disponibilidade diferenciada de água no solo. Relações hídricas de plantas em tubetes. Revista Árvore, v.28, n.3, p.333-341, 2004. Disponível em: <http://dx.doi.org/10.1590/ S0100-67622004000300003>. Acesso em: 10 out. 2011. doi. 10.1590/S0100-67622004000300003.

CHAVES, M.M. et al. How plants cope with water stress in the field Photosynthesis and growth. Annals of Botany, v.89, p.907-916, 2002. Disponível em: <http://aob.oxfordjournals. org/content/89/7/907.abstract>. Acesso em: 21 jan. 2012. doi. doi: $10.1093 / \mathrm{aob} / \mathrm{mcf} 105$.

LAWLOR, D.W. Limitation to photosynthesis in water - stressed leaves: Stomata vs. metabolism and the role of ATP. Annals of Botany, v.89, p.871-885, 2002. Disponível em: <http://aob. oxfordjournals.org/content/89/7/871.abstract>. Acesso em: 21 jan. 2012. doi. $10.1093 / \mathrm{aob} / \mathrm{mcf} 110$.

LAWLOR, D.W.; CORNIC, G. Photosynthetic carbon assimilation and associated metabolism in relation to water deficits in higher plants. Plant, Cell and Environment, v.25, p.275-294, 2002. Disponível em: <http://onlinelibrary.wiley.com/doi/10.1046/ j.0016-8025.2001.00814.x/pdf>. Acesso em: 10 mar. 2012. doi. 10.1046/j.0016-8025.2001.00814

LARCHER, W. Ecofisiologia vegetal. Tradução: PRADO, C.H.B.A. São Carlos: Rima, 2006. 531p.

LIMA, W.P. Impacto ambiental do eucalipto. São Paulo: Universidade de São Paulo, 1996. 301p.

NI, B.; PALLARDY, S.G. Stomatal and non stomatal limitation to net photosynthesis in seedlings of woody angiosperms. Plant Physiology, v.99, p.1502-1508, 1992. Disponível em: <http:// www.ncbi.nlm.nih.gov/pmc/articles/PMC1080654/>. Acesso em: 10 mar. 2012. doi. PMC1080654.

NOGUEIRA, R.J.M.C. et al. Aspectos ecofisiológicos da tolerância à seca em plantas da caatinga. In: NOGUEIRA,
R.J.M.C. et al. (Ed.). Estresses ambientais: danos e benefícios em plantas. Recife: UFRPE, 2005. p.22-31.

PALLARDY, S.G. Physiology of woody plants. 3.ed. San Diego: Elsevier/Academic, 2008. 454p.

PEAK, D. et al. Evidence for complex, collective dynamics and emergent, distributed computation in plants. PNAS, v.101, n.4, p.918-922, 2004. Disponível em: <http://www.pnas.org/ content/101/4/918.abstract>. Acesso em: 10 abr. 2012. doi. 10.1073/pnas.0307811100.

PEEVA, V.; CORNIC, G. Leaf photosynthesis of Haberlea rhodopensis before and during drought. Environmental and Experimental Botany, v.65, n.2-3, p.310-318, 2009. Disponível em: <http://www.sciencedirect.com/science/article/pii/ S0098847208001275>. Acesso em: 16 abr. 2012. doi. 10.1016/j. bbr.2011.03.031.

SCHOLANDER, P.F et al. Sap pressure in vascular plants. Science, v.148, n.3668, p.339-346, 1965. Disponível em: <http:// www.sciencemag.org/content/148/3668/339.abstract>. Acesso em: 9 set. 2011. doi. 10.1126/science.148.3668.339.

SILVA, W. et al. Condutância estomática de Eucalyptus citriodora e $\boldsymbol{E}$. grandis, em resposta a diferentes níveis de água no solo e de convivência com Brachiaria brizantha Stapf. Bragantia, v.57, n.2, p.339-347, 1998. Disponível em: <http://www.scielo.br/scielo. php?script=sci_arttext\&pid=S0006-87051998000200015\&lng $=$ pt\&nrm=iso $>$. Acesso em: 5 jun. 2011. doi. 10.1590/S000687051998000200015.

SILVA, M.A.V. et al. Resposta estomática e produção de matéria seca em plantas jovens de aroeira submetidas a diferentes regimes hídricos. Revista Árvore, v.32, n.2, p.335344, 2008. Disponível em: <http://www.scielo.br/scielo. php?script $=$ sci_arttext $\&$ pid $=$ S0100-67622008000200016\&lng =pt\&nrm=iso>. Acesso em: 2 abr. 2012. doi. 10.1590/S010067622008000200016

SILVEIRA, R.L.V.A. et al. Seja o doutor do seu Eucalipto. Piracicaba: Arquivo do agrônomo da Potafos, 2001. N.12. (Informações Agronômicas n.93).

SOUZA, C.R. et al. Trocas gasosas de mudas de videira, obtidas por dois porta-enxertos, submetidas à deficiência hídrica. Pesquisa Agropecuária Brasileira, v.36, n.10, p.12211230, 2001. Disponível em: <http://www.scielo.br/scielo. php?script=sci_arttext\&pid=S0100-204X2001001000002\&ln $\mathrm{g}=\mathrm{pt} \& \mathrm{nrm}=\mathrm{iso}>$. Acesso em: 2 abr. 2012. doi. 10.1590/S0100$204 X 2001001000002$.

TATAGIBA, S.D. et al. Relações hídricas e trocas gasosas na seleção precoce de clones de eucalipto para ambientes com diferenciada disponibilidade de água no solo. Floresta, v.38, n.2, p.387-400, 2008. Disponível em: <http://ojs.c3sl.ufpr.br/ojs2/ index.php/floresta/article/viewArticle/11633>. Acesso em: 22 mar. 2012

TATAGIBA, S.D. et al. Comportamento fisiológico de dois clones de Eucalyptus na época seca e chuvosa. Cerne, v.13, p.149-159, 2007. Disponível em: <http://www.dcf.ufla.br/cerne/publicacao. php? volume=13\&numero=2>. Acesso em: 22 mar. 2012. 